\title{
Color-Selective CMOS Photodiodes Based on Junction Structures and Process Recipes
}

\author{
Oscal T.-C. Chen and Wei-Jean Liu \\ National Chung Cheng University \\ Taiwan
}

\section{Introduction}

In the manufacture process of image sensors, it is commonly used to fabricate photodiodes with sensing different colors such as red, green and blue by means of color filters. Since each photodiode only senses a specific color, the back-end image processing mechanism is employed to restore the original color image. However, existence of color filters not only degrades photo-responses of photodiodes but it also makes the fabrication process complicated, thus increasing the fabrication cost.

The image sensor can be partitioned into two parts of the front-end photodiode array and the back-end signal processing circuit where its architecture can be depicted in Fig. 1. Each photodiode is connected to an amplifier that transfers the captured image signal into an electrical signal. Additionally, an overall photodiode array is established by using a pattern with red, green and blue photodiodes as shown in Fig. 1 according to the human perceptual principle [1], [2]. As for the signal processing part, it comprises a decoder, timing-control unit, compensating and synthesizing circuit and so on. The conventional color photodiode is displayed in Fig. 2, which is built by a layer of the light-filtration material as well as the general standard process, to yield the desired color. Such a fabrication method makes a photodiode having a large response toward a specific wavelength and lessening responses of the unneeded wavelengths. Let's take the commonly-used red, green and blue filters as an example. These three color photodiodes exhibit the photo-responses shown in Fig. 3. It is apparent that peak wavelengths of spectral responses appear in regions of red $(670 \mathrm{~nm})$, green $(550 \mathrm{~nm})$ and blue $(470 \mathrm{~nm})$. However, such a fabrication method has the following drawbacks.

1. The fabrication process requires the extra steps in addition to the original standard process. That is to say, the extra several masks are required when color filters are added on top of the commonly-used standard fabrication process, which increase the manufacture cost.

2. Most of incident light is absorbed and reflected during passing through the color filter that decreases the photo-response of a photodiode. Accordingly, one extra process of micro lens is included for the commonly-used color filter to focus incident light with the purpose of increasing the induced current.

3. In order to meet the requirement of sensing different colors, the process must provide different color filters that increase the degree of difficulty on fabrication process. To integrate with micro lens, the fabrication process should be modified in extra when 
there is a larger degree of alteration for the sensing area of a photodiode that yields a better response under a specific curvature radius of the lens.

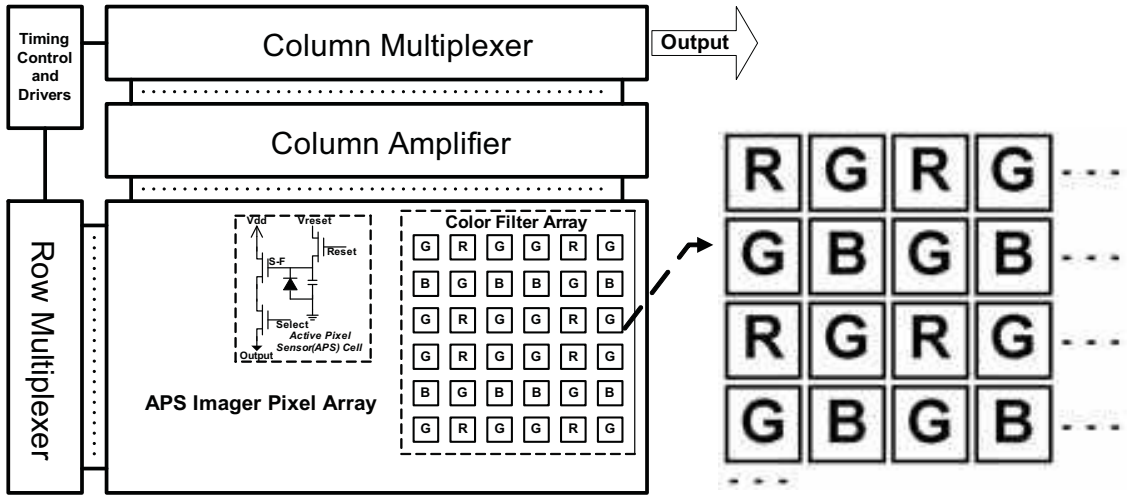

Fig. 1. Architecture of a CMOS image sensor with a color pixel array arranged in the form of the Bayer's pattern [1].

\section{Color Filter \\ Photodiode}

Fig. 2. Simplified structure of the conventional photodiode with a color filter.

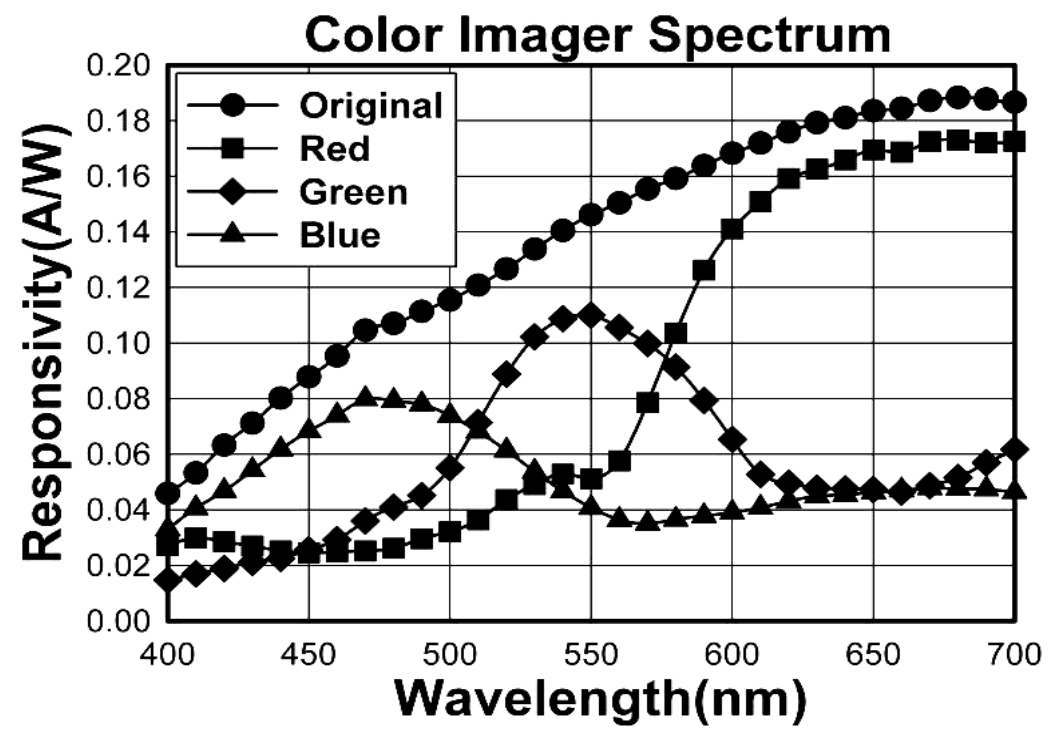

Fig. 3. Commonly-used red, green and blue filters and their corresponding spectral responses. 
Despite of the abovementioned three drawbacks, the color filter should be designed by taking into consideration photo-sensing characteristics of the material itself because each photo-sensing material has non-uniform responses toward different wavelengths of incident light. On the other hand, the back-end color compensation circuit is developed with considering characteristics of color filters, mainly the transmission ratio of incidence light, which makes the overall design highly complicated. From the abovementioned issues, it is understood that there still are many drawbacks in the conventional fabrication process which needs to be improved.

To overcome these disadvantages, Chang et al. proposed a color-sensing phototransistor with a hetero-junction structure based on the hydrogenated amorphous silicon (a-Si:H) [3]. By controlling the voltage drop from $13 \mathrm{~V}$ to $1 \mathrm{~V}$ between a collector and an emitter in a phototransistor, the peak wavelength varies from $610 \mathrm{~nm}$ to $420 \mathrm{~nm}$. Tasi et al. proposed a structure employing a change in the external bias polarity of the collector and emitter of a phototransistor. The peak wavelength varies from $600 \mathrm{~nm}$ to $450 \mathrm{~nm}$ under a biased voltage from $-2 \mathrm{~V}$ to $2 \mathrm{~V}$ [4]. Since a-Si:H provides advantages of high photosensitivity in a visible light region and low-cost fabrication, it is extensively employed in the bias-controlled photosensing devices [3]-[10]. However, a-Si:H suffers from the Staebler-Wronski effect which results in light-induced instability, and it is not suited to the application of circuit implementation [11]. To overcome this drawback, some researchers proposed the technology of the Thin Film on ASIC (TFA) to combine a-Si:H and crystalline silicon, which are utilized in photo-sensing and electric devices, respectively [12], [13]. This technology successfully provides both advantages of high sensitivity and high integration from a-Si:H and CMOS process, respectively. Moreover, such a technology also successfully replaces color filters by controlling biased voltages.

Recently, some researchers investigated color CMOS image sensors using the standard CMOS process without color filters [14]-[18]. For example, Findlater et al. employed a double junction photodiode to approach a color CMOS image sensor [15]. Particularly we also developed a CMOS photodiode by shorting a p-n junction to approach multiple spectral responses in a single CMOS photodiode [16]. Moreover, color CMOS image sensors implemented by the standard CMOS process without color filters were successfully realized [14], [17], [18]. It indicates that a color CMOS image sensor can be implemented with lower cost and higher integration than the conventional ones.

In this chapter, the spectral responses of various CMOS photodiodes are explored and compared. Additionally, the proposed model is employed to investigate the reasons of spectral responses varied with different CMOS photodiodes. An epitaxial layer that can lower the crosstalk among pixels and degrade the spectral response in the infrared region is usually utilized in CMOS image sensors [19]. Moreover, the thickness and doping concentration of the epitaxial layer can be adjusted to achieve the desired spectral response for specific image sensors without color filters [20], [21]. Hence, the epitaxial affect on the spectral responses is also examined. Since the spectral response of a-Si:H photodiodes can be easily varied by controlling biased voltages, the biased voltage effect on the spectral responses of CMOS photodiodes is also investigated. Finally, the design methodology is presented to address a specific spectral response on CMOS photodiodes without color filters.

\section{Structures and applications of various CMOS photodiodes}

The standard CMOS process is employed to fabricate photodiodes in this work. In the current CMOS process, there exist several types of CMOS compatible photodiodes [22]. 
Figure 4 depicts cross sections of the process. Generally, there exists four types of CMOS photodiodes: n+/p-/p-sub, n-/p-sub, p+/n-/p-sub and p+/n- shown in Figs. 4(a) and 4(b) under the general and epitaxial wafers, respectively. To meet the demands of various applications, photodiodes in CMOS image sensors have been designed using different process recipes and junction structures. Particularly, a CMOS photodiode with an $n-/ p$-sub or $\mathrm{p}^{+} / \mathrm{n}$ - junction is often applied to CMOS image sensors [15], [23]-[26]. Since the spectral response of silicon covers visible light and infrared regions, $\mathrm{n}-/ \mathrm{p}$-sub and $\mathrm{p}^{+} / \mathrm{n}-/ \mathrm{p}-\mathrm{sub}$ photodiodes can be used in commercial CMOS image sensors. Owing to the junction between $\mathrm{n}$ - and $\mathrm{p}$-substrate deeper than that between $\mathrm{p}^{+}$and $\mathrm{n}-$, the $\mathrm{n}-/ \mathrm{p}$-sub junction is more responsive in the infrared region $(>800 \mathrm{~nm})$ than the $\mathrm{p}^{+} / \mathrm{n}$ - junction. Accordingly, the $\mathrm{n}$-/p-sub photodiode can serve as an infrared detector as well as a visible light detector [27], [28].

$\mathrm{A}^{+} / \mathrm{n}$-/p-sub photodiode with a particular recipe that enables the whole $\mathrm{p}^{+}$layer to be fully depleted, can function like a pinned photodiode to improve the sensitivity at short wavelengths and reduce the thermal noise at its surface [29]. Two $p-n$ junctions, $\mathrm{p}^{+} / \mathrm{n}-$ and $\mathrm{n}-/ \mathrm{p}$-sub, of the $\mathrm{p}^{+} / \mathrm{n}-/ \mathrm{p}$-sub photodiode can form a pnp phototransistor, which yields a high gain through a transistor action [30]-[32]. An epitaxial layer that can lower the crosstalk among pixels is usually utilized in CMOS image sensors. Particularly, the epitaxial may degrade quantum efficiency of the CMOS photodiode with $\mathrm{p}$-epi/p+sub in the infrared region [33]. Additionally, the thickness and doping concentration of the epitaxial layer can be adjusted to achieve the desired quantum efficiency for specific image sensors without color filters [34].

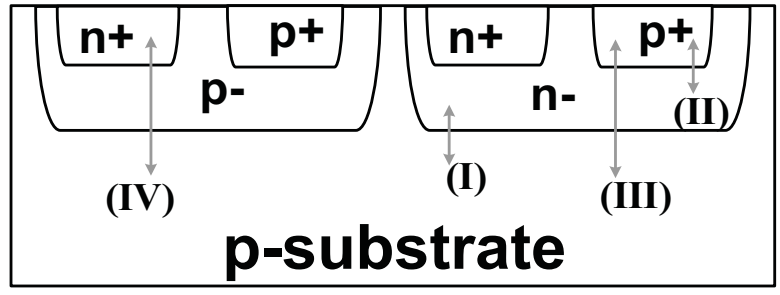

(a)

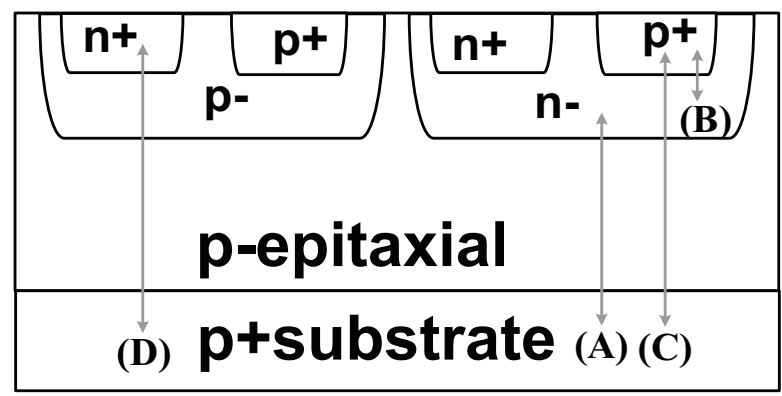

(b)

Fig. 4. Simplified structures of the standard CMOS processes with four types of photodiodes in (a) General wafer and (b) Epitaxial wafer. 


\section{Analyses and measured results of common-used CMOS photodiodes}

There are two main factors, the structure and recipe of a photodiode and the reverse biased voltage, affecting spectral responses of CMOS photodiodes. In this section, these two factors are investigated to understand variations of spectral responses.

\section{A. Effects from photodiode structure and recipe}

CMOS photodiodes are studied in terms of the depth of the p-n junction, doping concentration and substrate type. The measured spectral responses of four CMOS photodiodes in Fig. 4(a) under a zero biased voltage are depicted in Fig. 5 to interpret the variations caused by depth of the $\mathrm{p}-\mathrm{n}$ junction and doping concentration. In this figure, spectral responses of $\mathrm{n}-/ \mathrm{p}$-sub and $\mathrm{p}^{+} / \mathrm{n}-/ \mathrm{p}$-sub are similar except for those in the short wavelength region. The reason for this phenomenon is that the excess minority carriers in the device surface, which are excited by incident light with short wavelengths, recombine rapidly owing to heavy doping in the $\mathrm{p}^{+}$layer. The surface recombination velocity is significantly influenced by process factors such as surface roughness, surface contamination and oxidation temperature, some of which are not easily controlled [35], [36]. Omitting reflection coefficients, Fig. 6 depicts the simulated spectral responses of the n-/p-sub under different surface recombination velocities. Since excess minority carriers in the device surface are excited by incident light with short wavelengths, and the recombination probability of these excited carriers increases with surface recombination velocity, the degraded amount of spectral response in short wavelengths is larger than that for long wavelengths.

Curve (IV) in Fig. 5 depicts that the spectral response of $\mathrm{n}^{+} / \mathrm{p}$ - photodiode reduces significantly in the long wavelength region. The reason of this phenomenon is caused by absorption coefficient. The relationship between absorption coefficient and light wavelength for silicon material can be approximately formulated as [37]

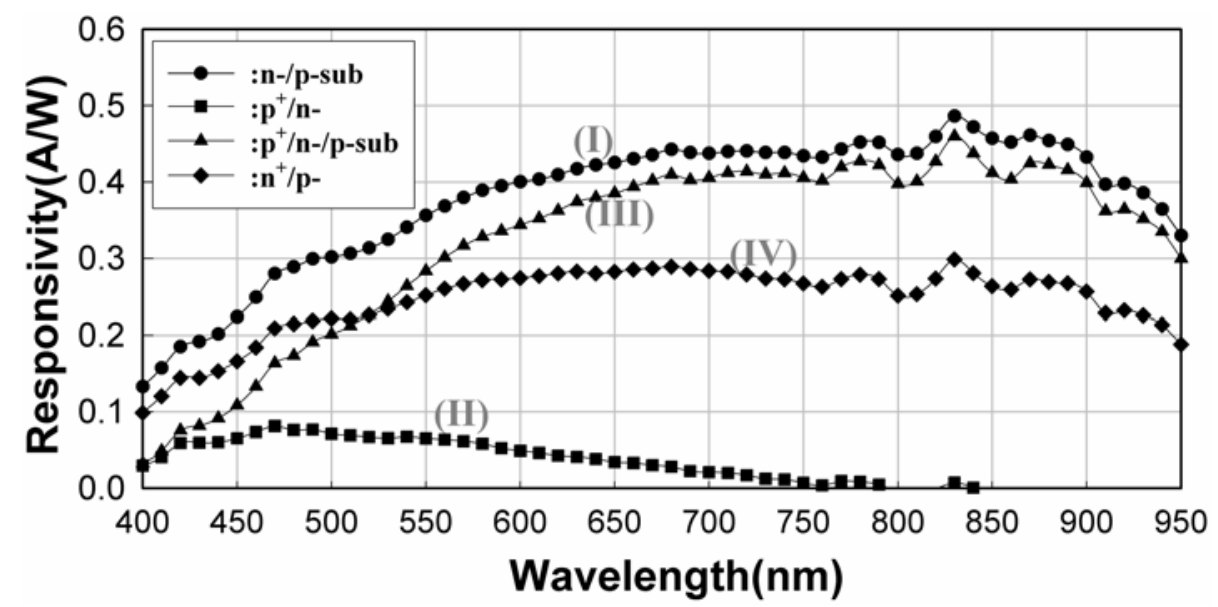

Fig. 5. Measured spectral responses of four CMOS photodiodes in Fig. 4(a) under zero biased voltage. 


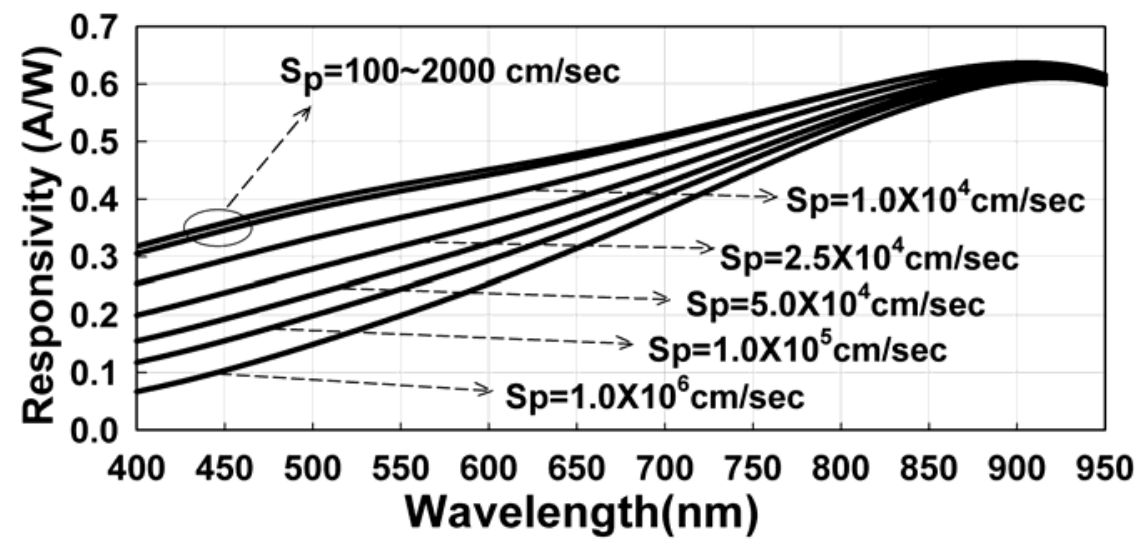

Fig. 6. Simulated spectral responses of $n-/ p$-sub under different surface recombination velocities where $\mathrm{Sp}$ indicates a surface recombination velocity.

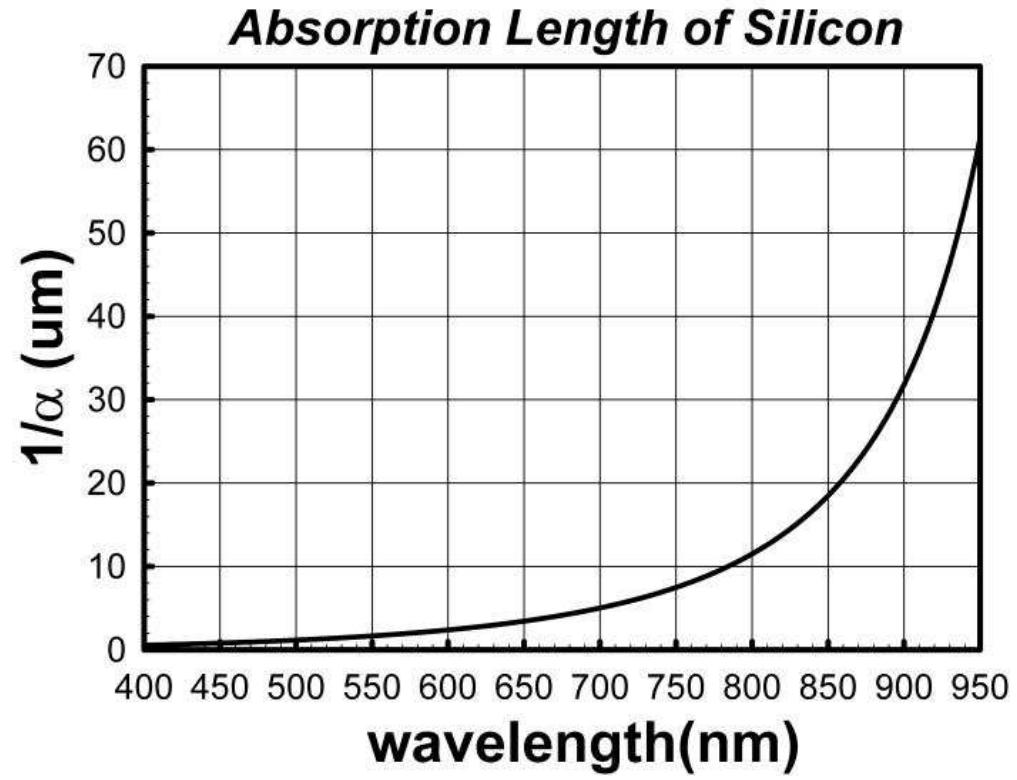

Fig. 7. Simulated result of the relationship between the incident light wavelength and absorption length.

$$
\alpha=\left(\frac{84.732}{\lambda}-76.417\right)^{2} .
$$

The reciprocal of absorption coefficient is absorption length that indicates the length where the photon flux decays to 1 /e of the previous one. Figure 7 shows the simulated result of the relationship between the incident light wavelength and absorption length. The excess minority carriers need diffuse to the boundary of the space-charge region and drift over the 
space-charge region to become an effective photocurrent. The p-n junction depth of $n^{+} / p-$ photodiode is about several hundreds of nanometers. Most of the induced excess minority carriers excited by incident light with long wavelengths can not diffuse to the $\mathrm{p}-\mathrm{n}$ junction to generate photocurrents. Hence, the spectral response of $\mathrm{n}^{+} / \mathrm{p}$ - photodiode is small in the long wavelength region. Additionally, curve (II) in Fig. 5 is apparently different from the other three ones. In this structure, all of the induced excess minority carriers excited in the psubstrate can not generate photocurrents. The photocurrent is produced only by the excess minority carriers excited by short wavelengths in the shallow region. Hence, comparing the spectral responses of other three photodiodes, the spectral response of this one is significantly small. Additionally, the peak wavelength of the spectral response apparently shifts to the short wavelength region $(460 \mathrm{~nm})$. In fact, since this $\mathrm{p}^{+} / \mathrm{n}-/ \mathrm{p}$-sub photodiode comprises two $\mathrm{p}-\mathrm{n}$ junctions of $\mathrm{p}^{+} / \mathrm{n}$ - and $\mathrm{n}-/ \mathrm{p}$-sub. The total spectral response is formed by adding the spectral response of these two p-n junctions. The spectral response from one of two p-n junctions can be effectively acquired by shorting the other p-n junction, as shown in Fig. 8. As a p-n junction is shortened, the electron-hole pairs recombine to make the junction current become zero such that there exist two kinds of shorting connection manners in this photodiode in Figs. 8(a) and (b) to yield two photo-responses in curves (II) and (III) of Fig. 5, respectively.

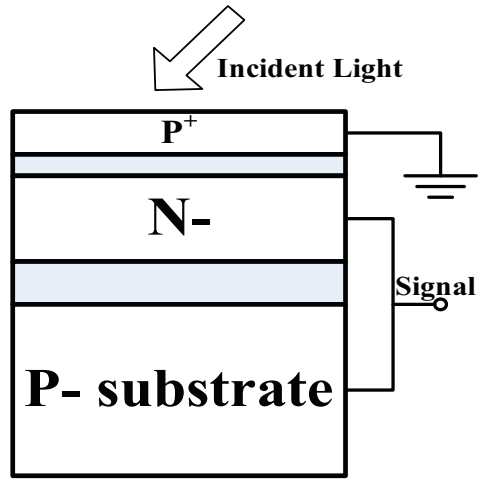

(a)

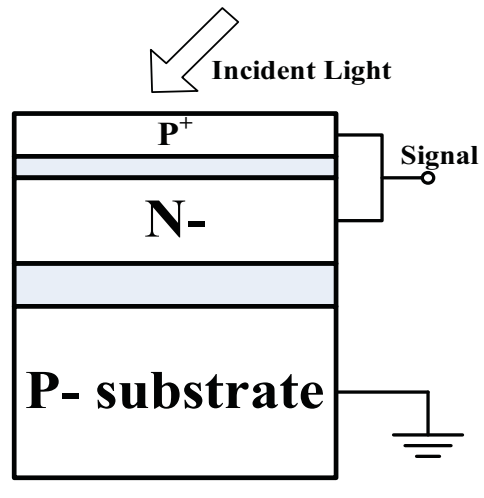

(b)

Fig. 8. Connection manners of the $\mathrm{p}^{+} / \mathrm{n}-/ \mathrm{p}$-sub photodiode for deriving different spectral responses: (a) Curve (II) and (b) Curve (III) in Fig. 5 [16].

The measurement results of the CMOS photodiodes shown in Fig. 4(b) is illustrated in Fig. 9. Comparing Figs. 5 and 9, the spectral responses of photodiodes with pepitaxial/p+substrate are much smaller than those with p-substrate in a long wavelength region. This difference is because the diffusion length of the minority carriers in p-substrate is as high as several hundred micrometers. Accordingly, most excess minority carriers in the p-substrate region generate the induced photocurrent. For the p-epitaxial/p+substrate structure, although the diffusion length of the minority carriers in the p-epitaxial region can also be as high as several hundred micrometers, most minority carriers in this region are transferred from p-epitaxial to $\mathrm{p}$ +substrate via drifting or diffusion. However, as the diffusion length of minority carriers in p+substrate is only several micrometers, most minority carriers in $\mathrm{p}+$ substrate are rapidly recombined so that the minority carriers cannot 
form an induced photocurrent. Hence, Fig. 9 also depicts that spectral responses begin to decay dramatically in the infrared region. Figure 10 displays the simulations associated with the excess minority carrier densities in p-substrate and p-epitaxial/p+substrate. From this figure, the excess minority carrier density in the p-substrate region is significantly higher than that in the p-epitaxial/p+substrate region. Particularly, the thickness and doping concentration of epitaxial can be adjusted to obtain the desired spectral response for applications of digital color image sensors without color filters [20], [21].

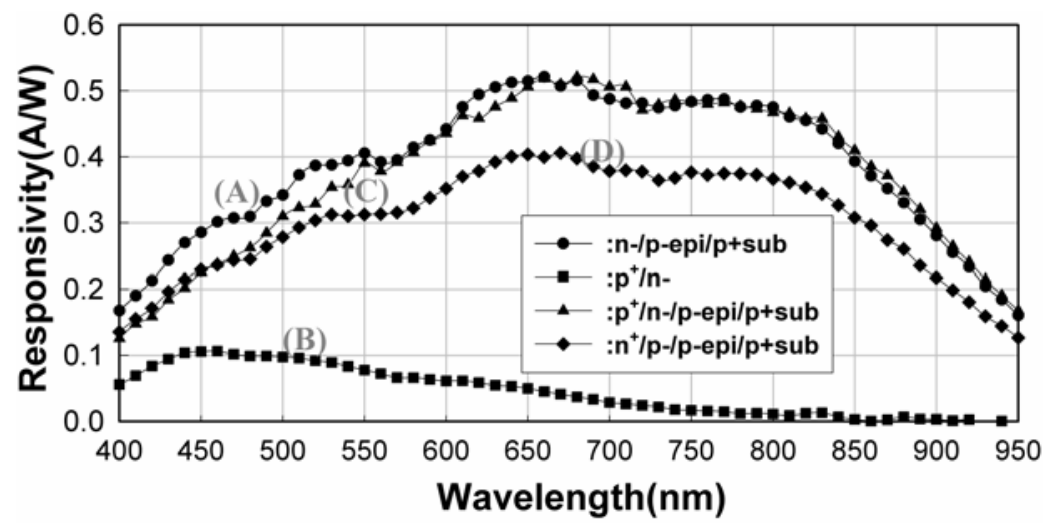

Fig. 9. Measured spectral responses of four CMOS photodiodes in Fig. 4(b) under zero biased voltage.

\section{B. Effects from reverse biased voltages}

In practice, to facilitate charge collection, a reverse biased voltage is often applied to photodiodes. The aforementioned measurement operations are conducted at a zero reverse biased voltage. In the following, the effect of the reverse biased voltage on the spectral response is investigated. The $n-/ p-s u b, p^{+} / n-/ p-s u b$ and $p^{+} / n-$ photodiodes in Fig. 4(a) and $\mathrm{n}$-/p-epi/p-sub photodiode in Fig. 4(b) are employed to observe the influence of reverse biased voltages on spectral responses of CMOS photodiodes with different structures. Figure 11 displays the measured spectral responses of these four photodiodes at reverse biased voltages of $0 \mathrm{~V},-1 \mathrm{~V},-3 \mathrm{~V}$ and $-5 \mathrm{~V}$. The spectral responses does not apparently increase for $\mathrm{n}-/ \mathrm{p}$-sub, $\mathrm{p}^{+} / \mathrm{n}-/ \mathrm{p}$-sub and $\mathrm{n}-/ \mathrm{p}$-epi/p-sub photodiodes under the absolute reverse biased voltage from $0 \mathrm{~V}$ to $-5 \mathrm{~V}$. In the $1-\mathrm{D}$ analysis, the reverse biased voltage only influences the vertical width of the space-charge region. Figure 12(a) shows the variations in the position of the space-charge region between $n$ - and p-substrate of the $n$-/ $\mathrm{p}$-sub photodiode at reverse biased voltages from $0 \mathrm{~V}$ to $-5 \mathrm{~V}$. The width of the space-charge region is increased with the absolute reverse biased voltage, such that two boundaries of the space-charge region extend into n- and p-substrate. Restated, the width of the neutral-region in n- and psubstrate declines as the absolute reverse biased voltage increases. Figure 13(a) depicts the simulated spectral responses of $\mathrm{n}$-, space-charge and p-substrate regions, and the total spectral responses at reverse biased voltages from $0 \mathrm{~V}$ to $-5 \mathrm{~V}$ when the reflection coefficient is zero. The spectral response in the space-charge region increases with the width of the region, while that in $\mathrm{n}$ - and p-substrate falls as the effective charge collection regions decrease in these two layers. In Fig. 13(a), the increase in the spectral response of the space- 


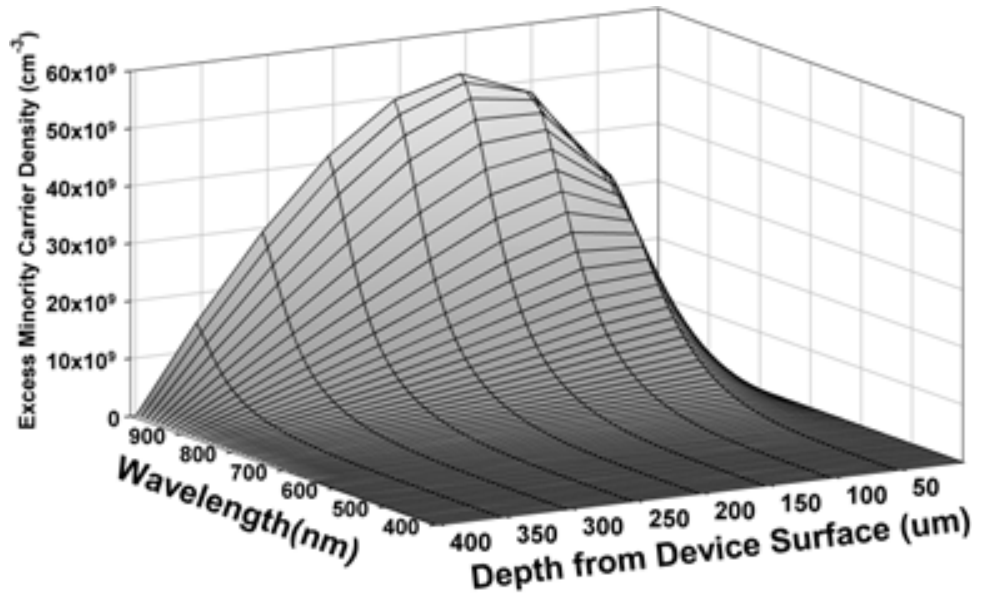

(a)

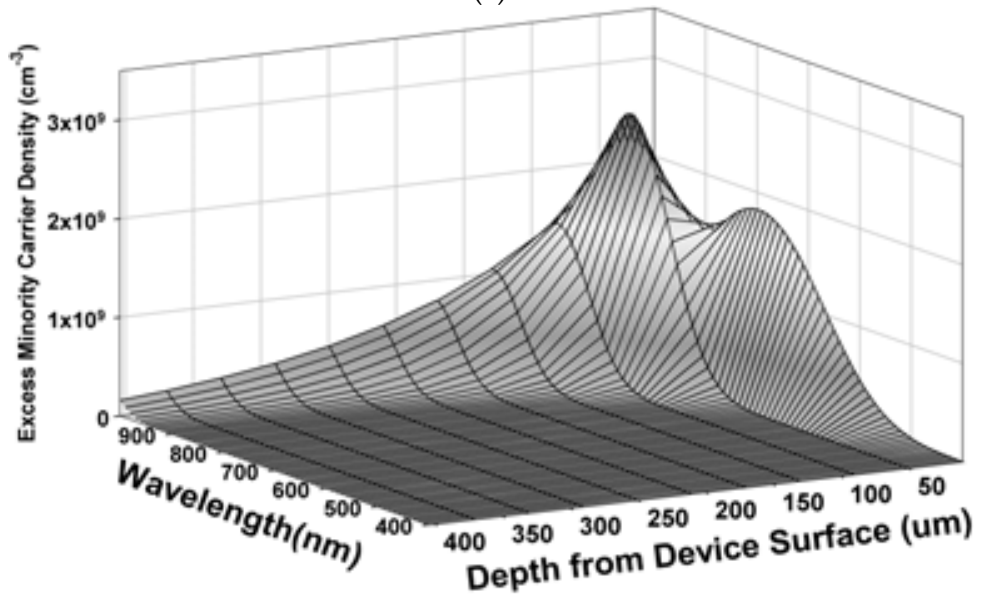

(b)

Fig. 10. Simulated excess minority carrier densities in (a) p-substrate and (b) pepitaxial/p+substrate.

charge region is nearly compensated for the drop in the spectral response of n- and $\mathrm{p}$ substrate. Hence, the spectral response of this photodiode slightly varies with the reverse biased voltage. The similar phenomenon is at $\mathrm{p}^{+} / \mathrm{n}-/ \mathrm{p}$-sub and $\mathrm{n}-/ \mathrm{p}-\mathrm{epi} / \mathrm{p}+\mathrm{sub}$ photodiodes as shown in Figs. 11(b) and 11(c). However, the event of the reverse biased voltage affecting the spectral response depends on the recipe and the current density distribution in each layer of a photodiode. Figure 11(d) displays the measured spectral response of $\mathrm{p}^{+} / \mathrm{n}$ - at reverse biased voltages of $0 \mathrm{~V},-1 \mathrm{~V},-3 \mathrm{~V}$ and $-5 \mathrm{~V}$. The spectral response increasing with the reverse biased voltage for this photodiode seems a bit more significantly and regularly than the other three photodiodes. Figure 12(b) depicts the variations in the position of the space-charge region of the $\mathrm{p}^{+} / \mathrm{n}$ - photodiode at reverse biased voltages from $0 \mathrm{~V}$ to $-5 \mathrm{~V}$. Since the variations of the effective charge collection regions in $\mathrm{p}^{+}$and $\mathrm{n}$ - are very 
small, the spectral response of this photodiode varies mainly by that generated in the spacecharge region. Because the spectral responses of $\mathrm{p}^{+}$and $\mathrm{n}$ - are decreased rarely little, the increase of the space-charge region dominates the effect of the reverse biased voltage on the

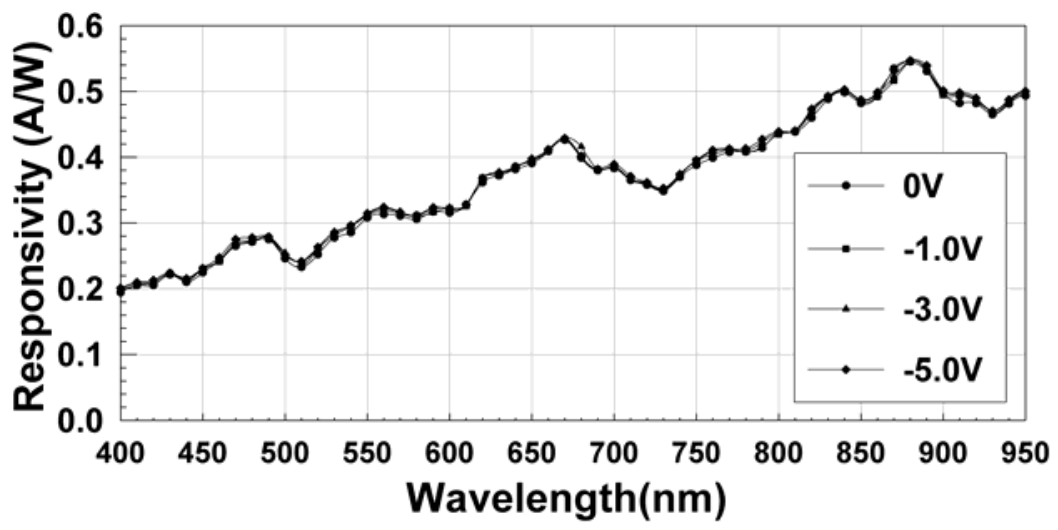

(a)

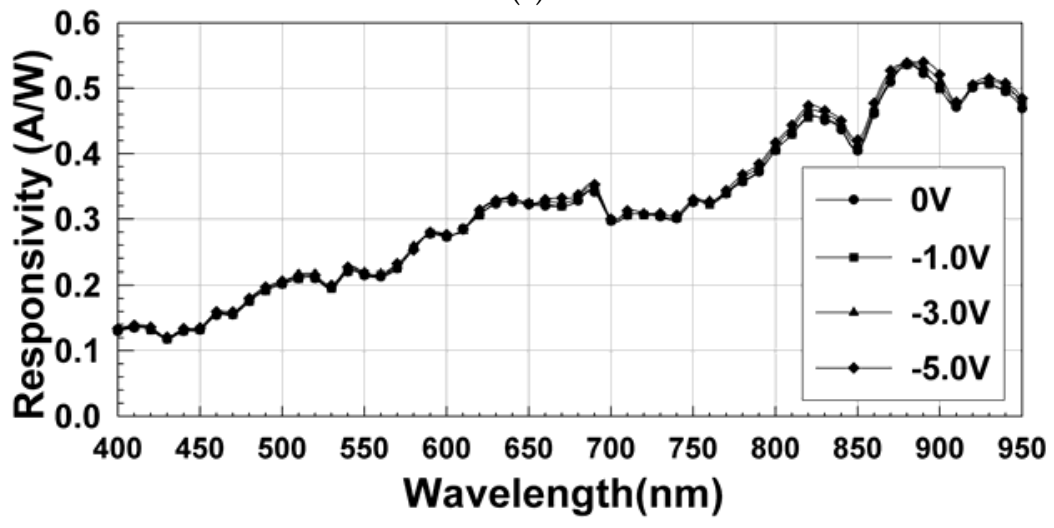

(b)

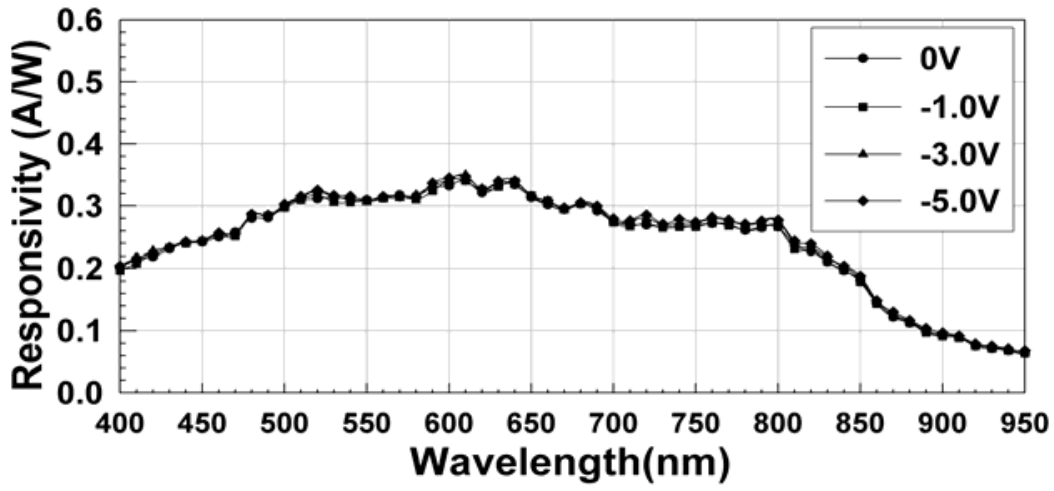

(c) 


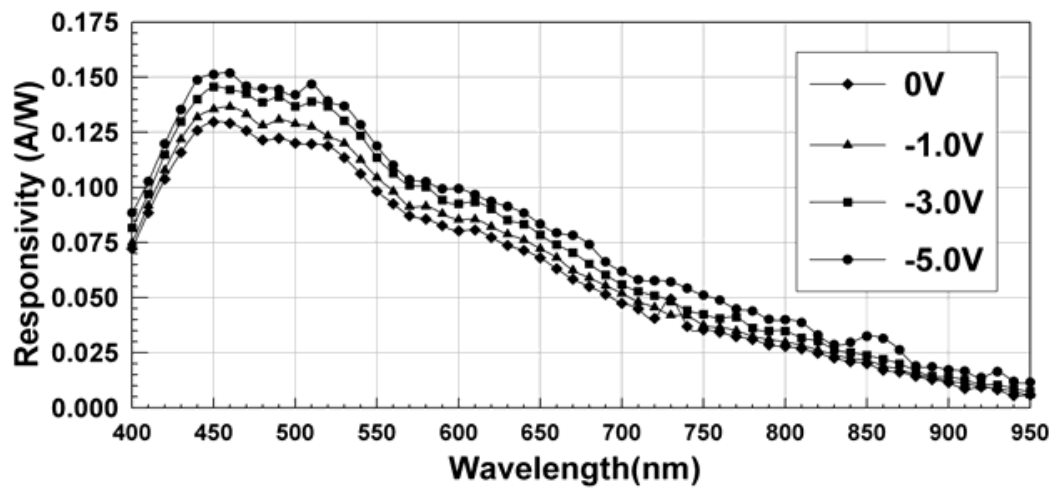

(d)

Fig. 11. Measured spectral responses of photodiodes under different reverse biased voltages in (a) n-/p-sub, (b) p $\mathrm{p}^{+} / \mathrm{n}-/ \mathrm{p}$-sub,(c) n-/p-epi/p+sub and (d) $\mathrm{p}^{+} / \mathrm{n}-$.

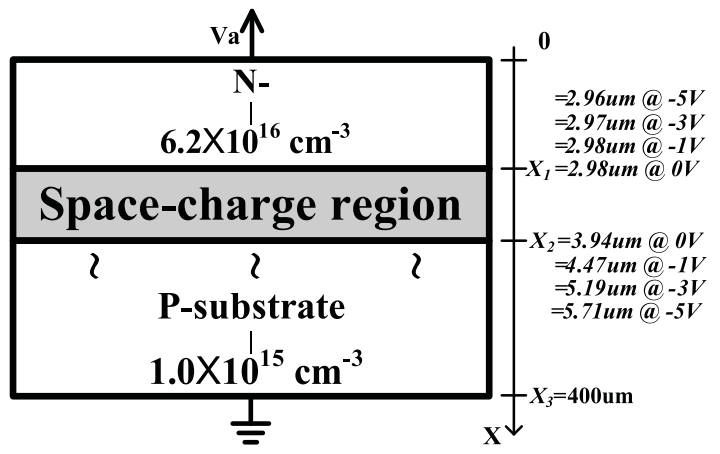

(a)

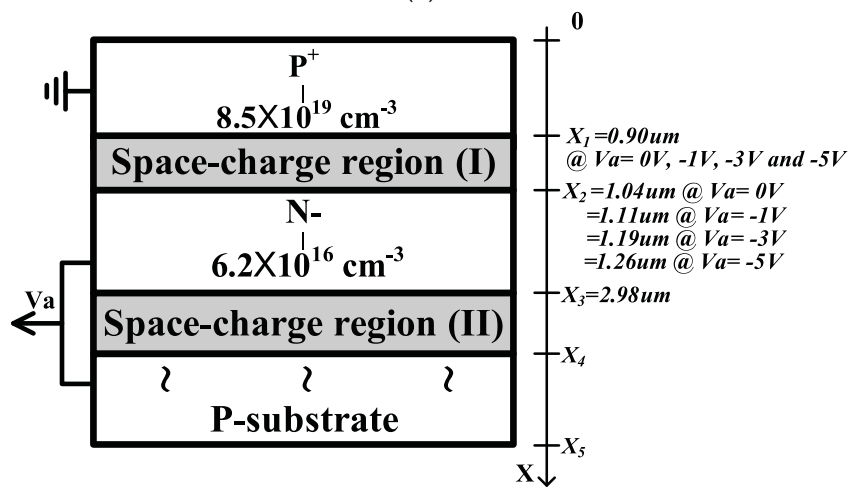

(b)

Fig. 12. Variations in positions of the space-charge regions of (a) $n-/ p$-sub photodiode and (b) $\mathrm{p}^{+} / \mathrm{n}$ - photodiodes, at reverse bias voltages from $0 \mathrm{~V}$ to $-5 \mathrm{~V}$ (the dimensions of each layer in this structure do not represent actual dimensions). 
spectral response. Figure 13(b) shows the simulated spectral responses of n-, space-charge, $\mathrm{p}$-substrate regions, and the total spectral responses at reverse biased voltages from $0 \mathrm{~V}$ to $5 \mathrm{~V}$ when the reflection coefficient is zero. The variation of the spectral response for this photodiode increases with the reverse biased voltage more significantly than those in the other three photodiodes.

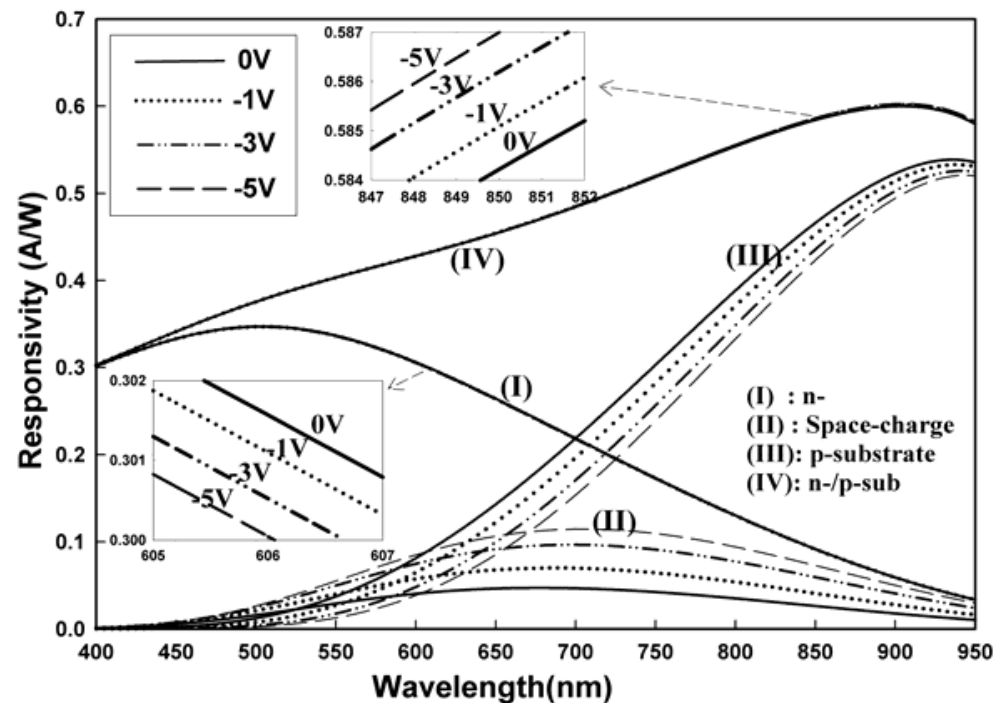

(a)

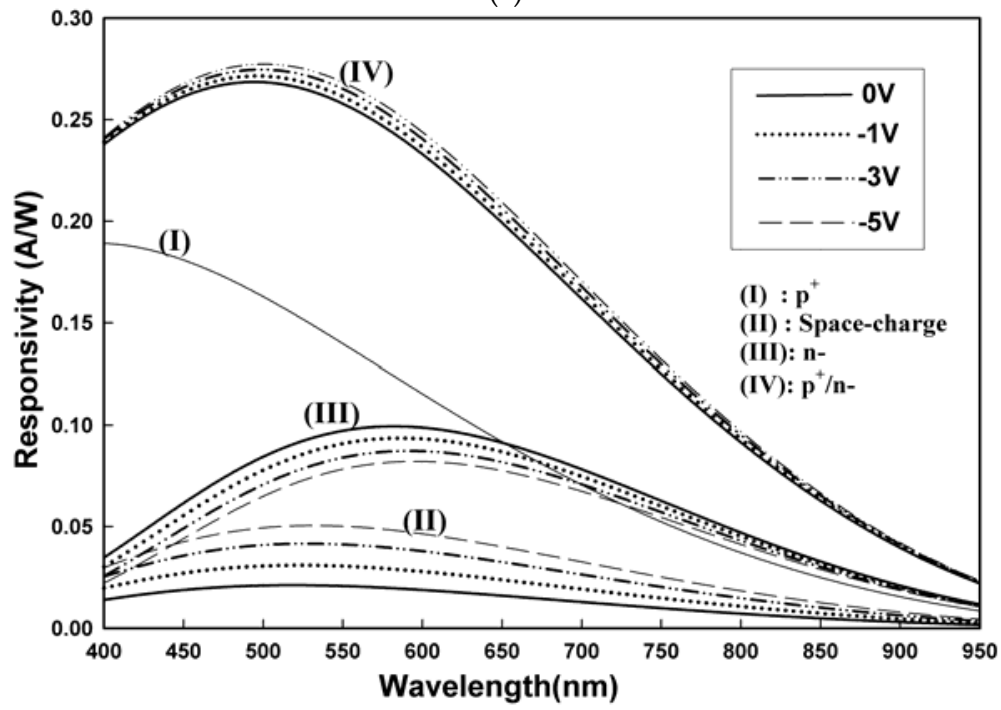

(b)

Fig. 13. Simulated spectral responses in n-type and p-type semiconductors and in spacecharge region under different reverse biased voltages ranging from $0 \mathrm{~V}$ to $-5 \mathrm{~V}$ when the reflection coefficient being zero for (a) n-/p-sub and (b) $\mathrm{p}^{+} / \mathrm{n}$ - photodiodes. 


\section{Design methodology for color CMOS pixels without color filters}

As the abovementioned, we conclude that the color filter technology is still a good choice for color separation presently. In fact, some specific modifications for the semiconductor process or signal processing circuits are applied to color CMOS image sensors without color filters [15]-[17]. In this work, an equation based on the CMOS photodiode model is derived to determine the peak wavelength of the spectral response. The detail of the derivation procedure is illustrated in Appendix. Here, some solutions for obtaining different color spectral responses are briefly sketched. Additionally, the approaches to enhance the capability of separating the color spectral responses are discussed.

1. Reducing the spectral response in the long wavelength region:

Generally, the thickness of the substrate is as thick as several hundreds of micrometers. Consequently, the spectral response is dominated by the induced photocurrent generated in the substrate region. Since the peak wavelength of the spectral response of substrate is generally located at the infrared region, the peak wavelength of the total spectral response tends to occur at the long wavelength region. There are two approaches to reduce the spectral response in the long wavelength region.

a. The spectral responses in the long wavelength region can be effectively decreased by shortening the p-n junction in the deep region [16]. The depth of diffusion affects the photodiode to absorb wavelengths of incident light. Referring to the absorption length in Fig. 7, the light with a longer wavelength penetrates to the deeper junction so that the incident light with a longer wavelength can excite electron-hole pairs at the deep region. However, to become photocurrents, the electron-hole pairs should reach to the boundary edges of the space-charge region successfully such that they would be absorbed and transformed to the photocurrent. In other words, the photodiode has a greater response toward the incident light with a longer wavelength at a deeper region whereas for a shallower region it has a better response toward the incident light with a shorter wavelength. Additionally, to prevent CMOS circuits from latch-up, p-substrate is generally connected to the lowest potential in the system. To keep the potential of p-substrate in the lowest level and the photodiode under reverse biased voltages, a connection manner depicted in Fig. 14 is employed to solve the problem of the voltage drop between $\mathrm{p}$ and $\mathrm{n}$ nodes in the photodiode. Figure 15 shows the simulated results utilizing the recipes in Fig. 14. It clearly reveals that the peak wavelength increases with the depth of the $\mathrm{p}^{+}$layer.

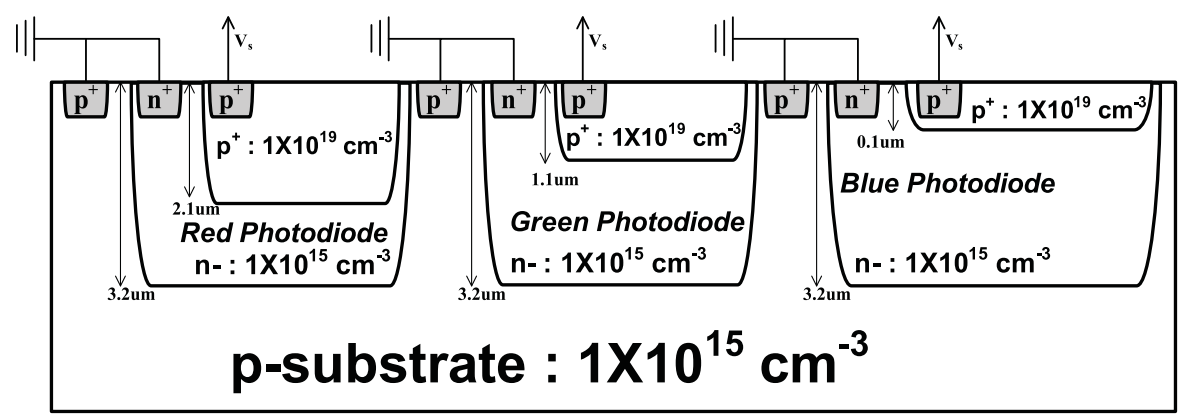

Fig. 14. Connection manner, recipes and structures obtaining three color spectral responses. 


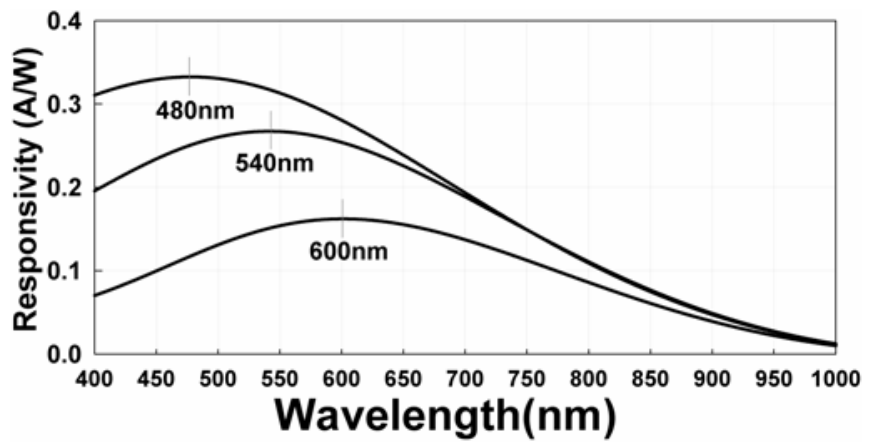

(a)

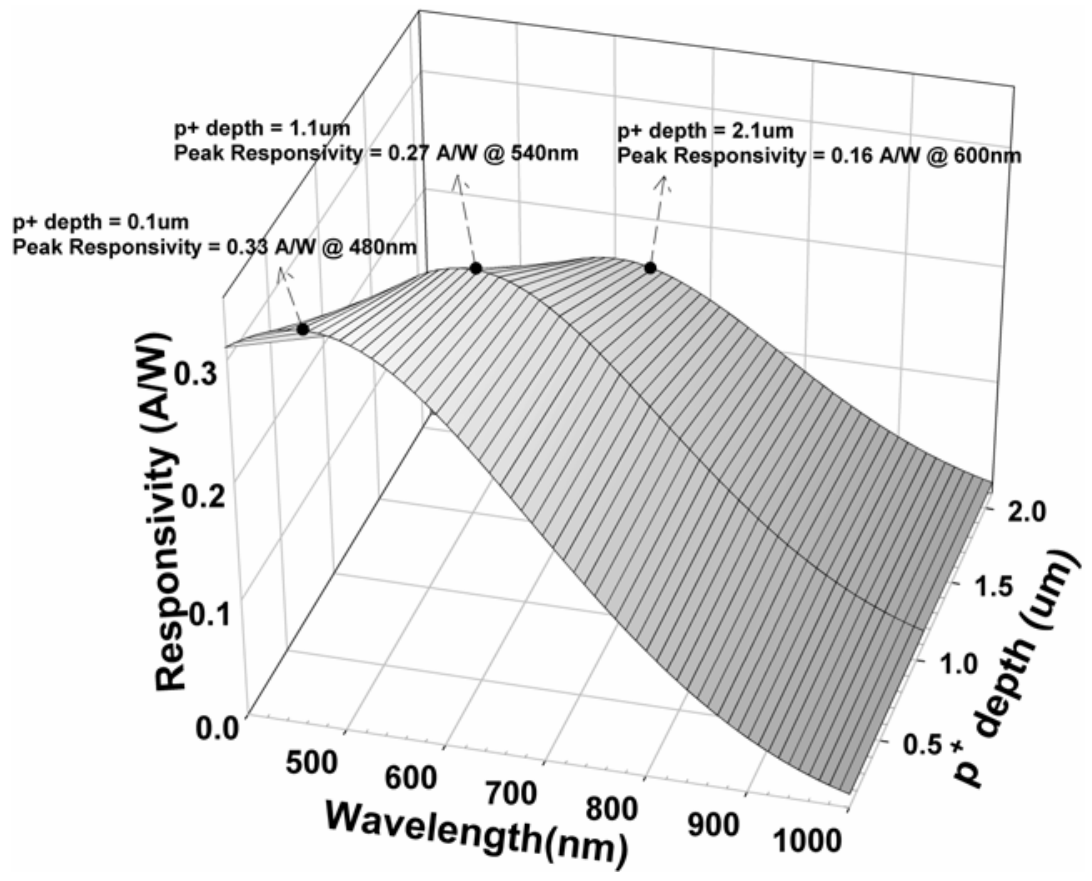

(b)

Fig. 15. Structures in Fig. 14 being simulated to yield (a) spectral responses of three recipes for red, green and blue photodiodes and (b) spectral responses of $\mathrm{p}^{+}$depth varying from $0.1 \mu \mathrm{m}$ to $2.1 \mu \mathrm{m}$.

b. The spectral response in the long wavelength region can be also lowered by reducing the thickness of the substrate layer to decrease the region for collecting excess minority carriers. Figure 16 depicts the $n-/ p$-sub photodiode with thin $p$ substrate of which the thickness is only several micrometers. Figure 17 displays the simulated results by utilizing the corresponding recipes in Fig. 16. It is apparent that the spectral response in the long wavelength region is decayed. 


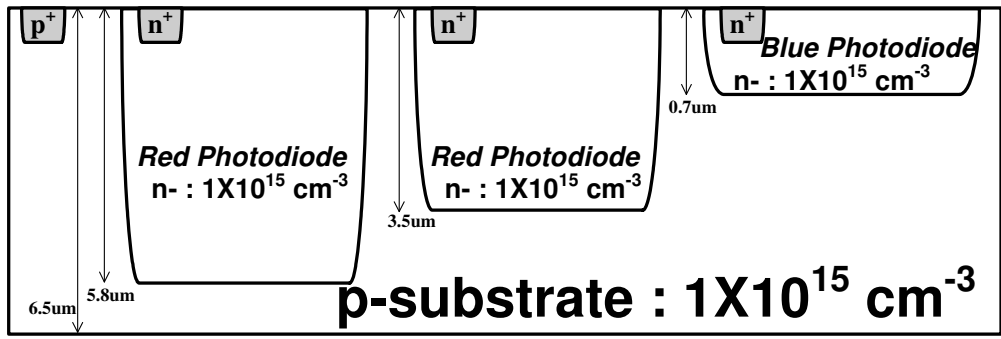

Fig. 16. Structures in Fig. 16 being simulated to yield (a) spectral responses of three recipes for red, green and blue photodiodes and (b) spectral responses of $n$ - depth varying from $0.7 \mu \mathrm{m}$ to $5.8 \mu \mathrm{m}$.

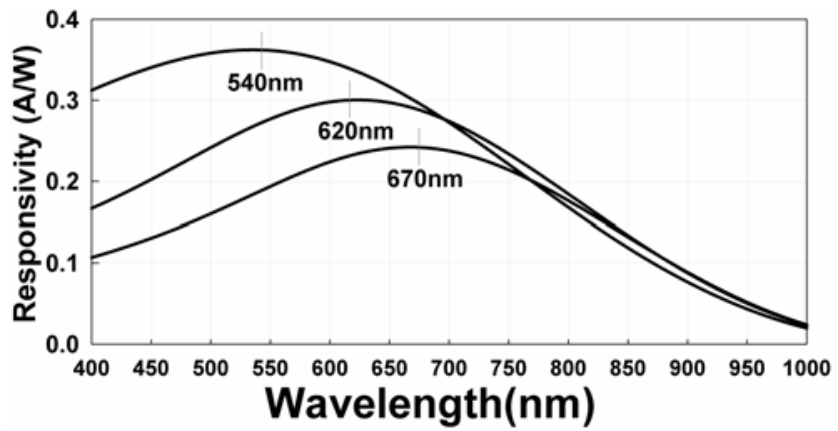

(a)

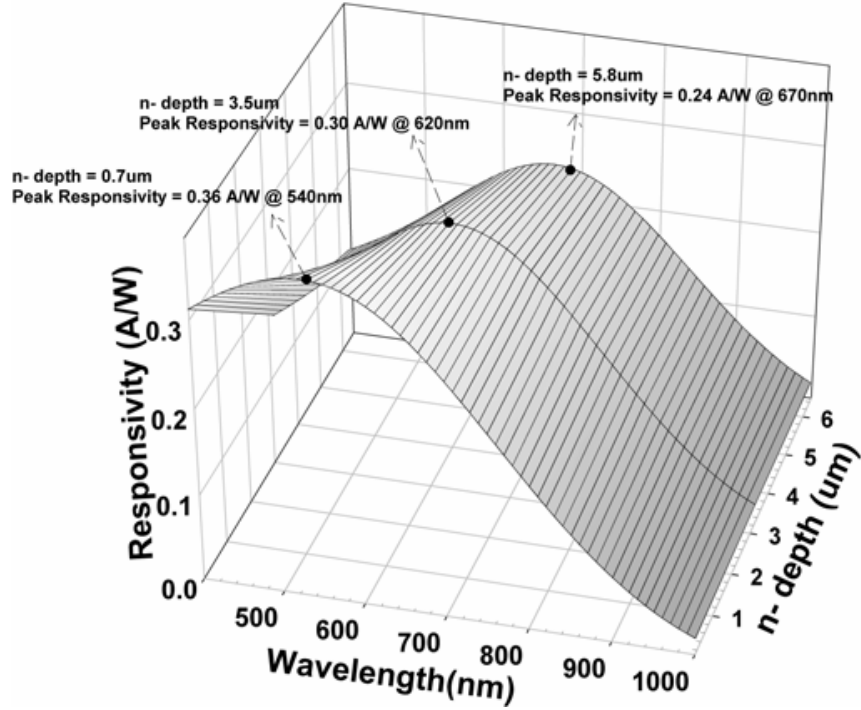

(b)

Fig. 17. Simulated results employing the structures in Fig. 16 under different recipes. 


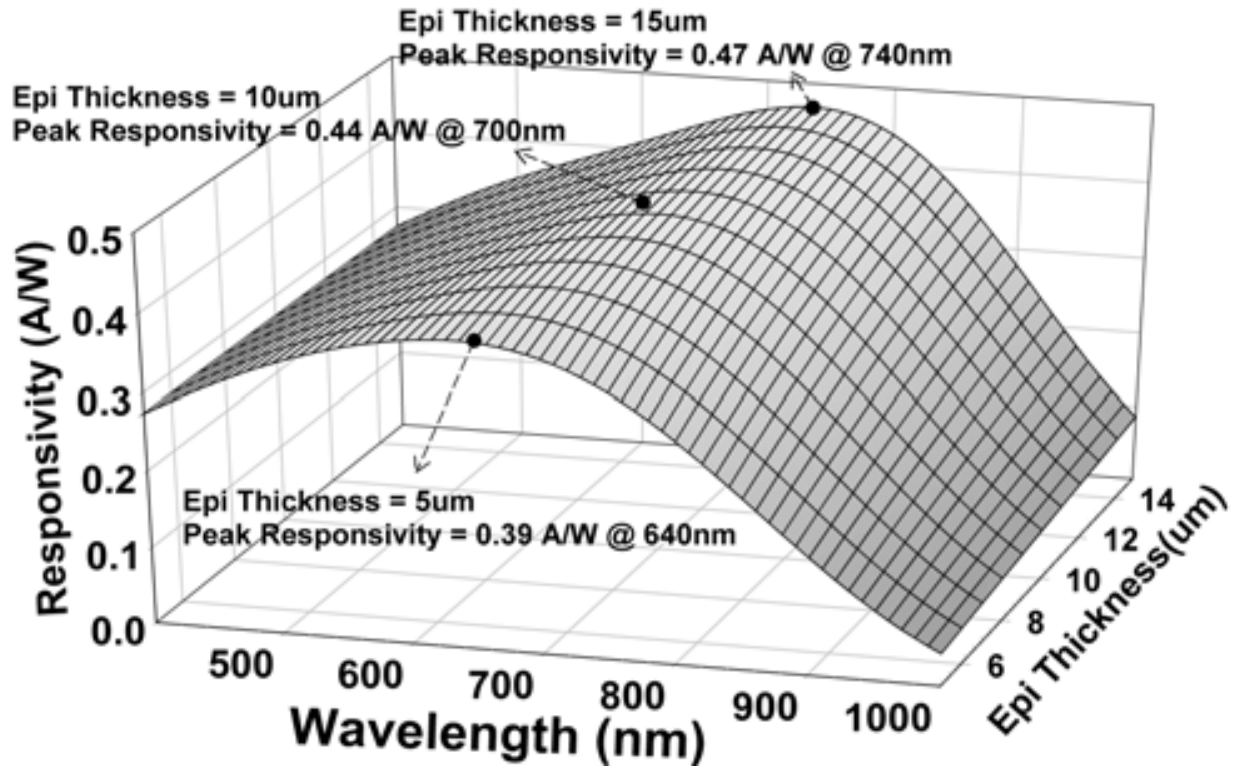

(a)

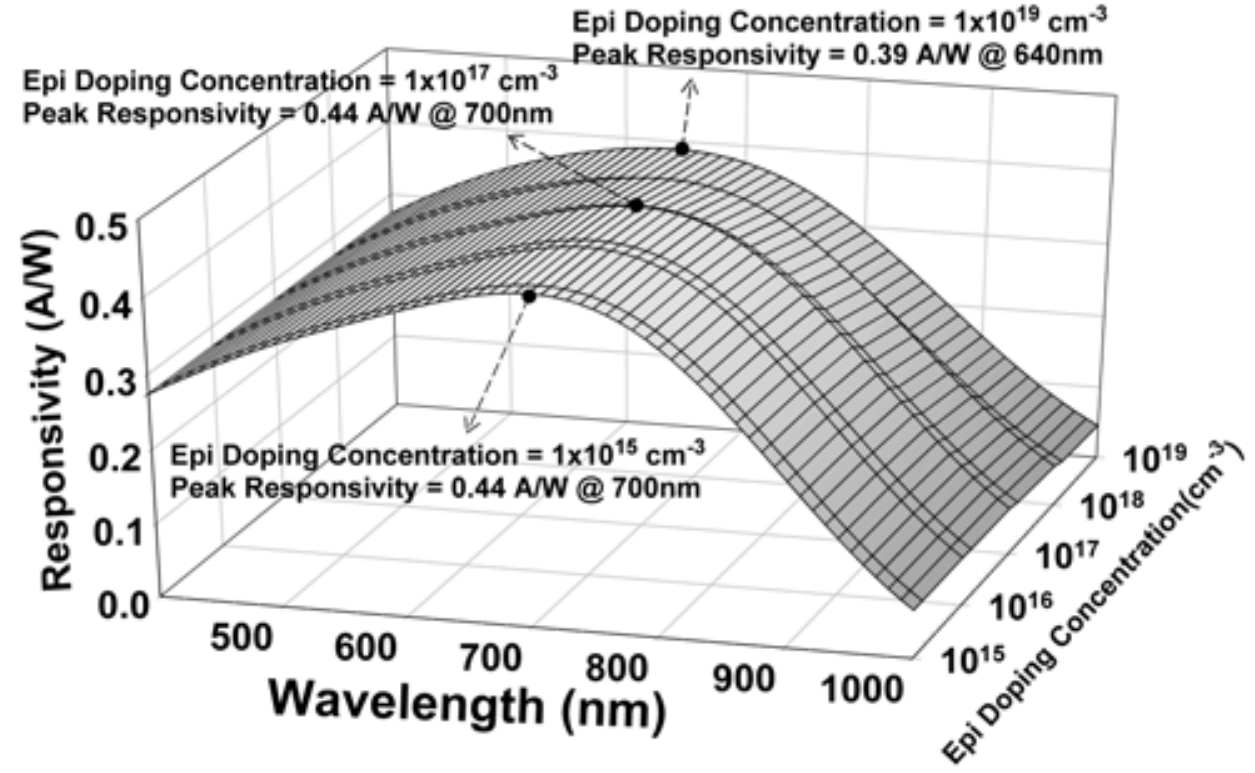

(b)

Fig. 18. Simulated spectral responses of the n-/p-epi/p+sub photodiode in (a) p-epitaxial doping concentration of $1 \times 10^{15} \mathrm{~cm}^{-3}$ and p-epitaxial thickness ranging from 5 to $15 \mathrm{um} \mathrm{um}$ and (b) p-epitaxial doping concentration ranging from $1 \times 10^{15} \mathrm{~cm}^{-3}$ to $1 \times 10^{19} \mathrm{~cm}^{-3}$ and pepitaxial thickness of $10 \mathrm{um}$. 
2. The spectral response in the long wavelength region can be decreased by heavy doping substrate associated with the p-epitaxial layer. By adjusting the depth of the epitaxial layer, the desired spectral response can be obtained. Figure 18 depicts the simulated spectral responses of the $\mathrm{n}-/ \mathrm{p}$-epi/p+sub photodiode under different thicknesses and doping concentrations of the epitaxial layer. According to this figure, the thickness and doping concentration of the epitaxial layer apparently affect spectral responses. In practice, some researchers proposed the approach of selective epitaxial growth to obtain various color spectral responses by changing the recipe of the epitaxial layer [20], [21].

\section{Conclusion}

Adaptive photodiode structures, of which design approach aiming at making the photoresponse having a peak value at a specific wavelength, that are realized by the photodiodes with color-selective mechanisms under the condition of without extra color filters is proposed. Moreover, the influences of color filters, photodiode structures, recipes and reverse biased voltages on spectral responses are investigated. Measurement results illustrate that the color filters affect the spectral responses more significantly than the others. The spectral response varies with the reverse biased voltages slightly. The approach of implementing color pixels using the standard CMOS process without color filters is also proposed. This work clearly paves the way for designers to realize color-selective pixels in CMOS image sensors.

\section{Appendix: Derivation for peak wavelength of the spectral response}

The n-/p-sub photodiode as shown in Fig. A.1 is employed to illustrate how the proposed model is used to derive the peak wavelength of the spectral response.

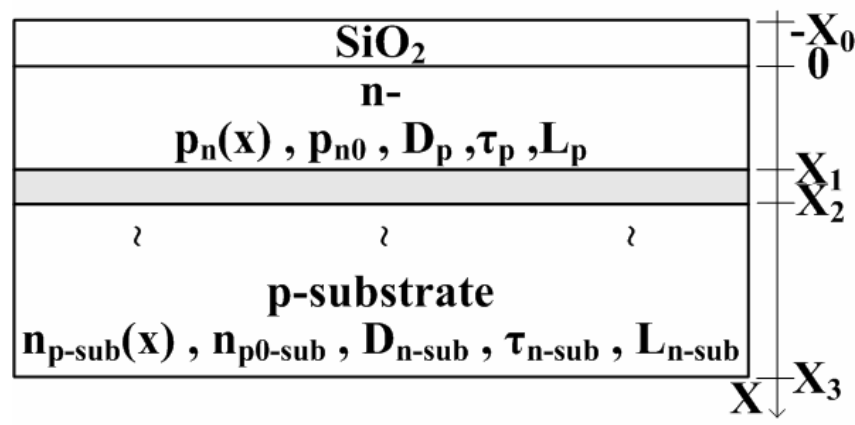

Fig. A.1 n-/p-sub photodiode.

The total current density generated by the $n-/ p$-sub photodiode is 


$$
\begin{aligned}
J_{\text {total }}= & J_{n-\text { photo }}+J_{p-\text { photo }}+J_{\text {drift }} \\
= & \left.q D_{p}\left(d p_{n-}(x)_{\text {photo }} / d x\right)\right|_{x=x_{1}}+\left.q D_{n-s u b}\left(d n_{p-\text { sub }}(x)_{\text {photo }} / d x\right)\right|_{x=x_{2}}+q \int_{x_{1}}^{x_{2}} G_{x} d x \\
= & \frac{q D_{p} \tau_{p} G_{0}}{L_{p}^{2} \alpha^{2}-1}\left(\frac{\left(\frac{e^{-\alpha x_{1}}}{L_{p}}\left(\frac{D_{p}}{L_{p}} \operatorname{sh}\left(\frac{x_{1}}{L_{p}}\right)+S_{p} \operatorname{ch}\left(\frac{x_{1}}{L_{p}}\right)\right)-\frac{\left(\alpha D_{p}+S_{p}\right)}{L_{p}}\right)}{\left(S_{p} \operatorname{sh}\left(\frac{x_{1}}{L_{p}}\right)+\frac{D_{p}}{L_{p}} \operatorname{ch}\left(\frac{x_{1}}{L_{p}}\right)\right)}+\alpha e^{-\alpha x_{1}}\right) \\
& +\frac{q L_{n-s u b} G_{0} e^{-\alpha\left(2 x_{2}+x_{3}\right)}\left(e^{\alpha\left(x_{2}+x_{3}\right)}\left(\alpha L_{n-s u b}+\operatorname{Coth}\left(\frac{x_{2}-x_{3}}{L_{n-s u b}}\right)\right)-e^{2 \alpha x_{2}} \operatorname{Csch}\left(\frac{x_{2}-x_{3}}{L_{n-s u b}}\right)\right)}{\left(L_{n-s u b}^{2} \alpha^{2}-1\right)} \\
& +q \phi_{0}\left(e^{-\alpha x_{2}}-e^{-\alpha x_{1}}\right)
\end{aligned}
$$

The absorption coefficient $\alpha$ can be simplifily represented as a function of the incident light wavelength, i.e. $\alpha=f(\lambda)$, and then Eq. (A1) can be modified to

$$
\begin{aligned}
J_{\text {total }}= & \frac{q D_{p} \tau_{p} G_{0}}{L_{p}^{2} f(\lambda)^{2}-1}\left(\frac{\left(\frac{e^{-f(\lambda) x_{1}}}{L_{p}}\left(\frac{D_{p}}{L_{p}} \operatorname{sh}\left(\frac{x_{1}}{L_{p}}\right)+S_{p} \operatorname{ch}\left(\frac{x_{1}}{L_{p}}\right)\right)-\frac{\left(f(\lambda) D_{p}+S_{p}\right)}{L_{p}}\right)}{\left(S_{p} \operatorname{sh}\left(\frac{x_{1}}{L_{p}}\right)+\frac{D_{p}}{L_{p}} \operatorname{ch}\left(\frac{x_{1}}{L_{p}}\right)\right)}+f(\lambda) e^{-f(\lambda) x_{1}}\right) \\
& \left.+\frac{q L_{n-s u b} G_{0}\left(e^{-x_{2} f(\lambda)}\left(f(\lambda) L_{n-s u b}+\operatorname{Coth}\left(\frac{x_{2}-x_{3}}{L_{n-s u b}}\right)\right)-e^{-x_{3} f(\lambda)} \operatorname{Csch}\left(\frac{x_{2}-x_{3}}{L_{n-s u b}}\right)\right)}{\left(L_{n-s u b}^{2} f(\lambda)^{2}-1\right)}\right) \\
& +q \phi_{0}\left(e^{-f(\lambda) x_{2}}-e^{-f(\lambda) x_{1}}\right)
\end{aligned}
$$

In Eq. (A2), the surface generation rate $G_{0}$ is

$$
G_{0}=\frac{\alpha P_{\text {in }} \lambda}{A h c}=\frac{f(\lambda) P_{\text {in }} \lambda}{A h c}
$$

Additionally, $A$ and $P_{\text {in }}$ in Eq. (A3) represent the unit area and unit incident light power, respectively. Hence, Eq. (A2) can be represented as follows. 


$$
\begin{aligned}
J_{\text {total }}= & \left.\frac{q D_{p} \tau_{p} f(\lambda) \lambda}{h c\left(L_{p}^{2} f(\lambda)^{2}-1\right)}\left(\frac{\left(\frac{e^{-f(\lambda) x_{1}}}{L_{p}}\left(\frac{D_{p}}{L_{p}} \operatorname{sh}\left(\frac{x_{1}}{L_{p}}\right)+S_{p} \operatorname{ch}\left(\frac{x_{1}}{L_{p}}\right)\right)-\frac{\left(f(\lambda) D_{p}+S_{p}\right)}{L_{p}}\right)}{\left(S_{p} \operatorname{sh}\left(\frac{x_{1}}{L_{p}}\right)+\frac{D_{p}}{L_{p}} \operatorname{ch}\left(\frac{x_{1}}{L_{p}}\right)\right)}+f(\lambda) e^{-f(\lambda) x_{1}}\right)\right) \\
& +\frac{q L_{n-\text { sub }} f(\lambda) \lambda}{h c\left(L_{n-s u b}^{2} f(\lambda)^{2}-1\right)}\left(e^{-x_{2} f(\lambda)}\left(f(\lambda) L_{n-s u b}+\operatorname{Coth}\left(\frac{x_{2}-x_{3}}{L_{n-s u b}}\right)\right)-e^{-x_{3} f(\lambda)} \operatorname{Csch}\left(\frac{x_{2}-x_{3}}{L_{n-\text { sub }}}\right)\right) \\
& +q \phi_{0}\left(e^{-f(\lambda) x_{2}}-e^{-f(\lambda) x_{1}}\right)
\end{aligned}
$$

The peak wavelength of the spectral response can be obtained by taking partial differential of Eq. (A4) by the variable of $\lambda$.

$$
\begin{aligned}
& \frac{\partial I_{\text {total }}}{\partial \lambda}= \\
& =\frac{q L_{p}}{h c}\left(\begin{array}{l}
\frac{e^{-f(\lambda) x_{1}} L_{p}\left(f(\lambda)\left(f(\lambda)^{2} L_{p}^{2}-1\right)\left(f(\lambda) D_{p}+S_{p}\right)-\lambda f^{\prime}(\lambda)\left(2 f(\lambda) D_{p}+S_{p}+f(\lambda)^{2} L_{p}^{2} S_{p}\right)\right)}{\left(L_{p}^{2} f(\lambda)^{2}-1\right)^{2}\left(D_{p} \operatorname{Cosh}\left(\frac{x_{1}}{L_{p}}\right)+L_{p} S_{p} \operatorname{Sinh}\left(\frac{x_{1}}{L_{p}}\right)\right)} \\
+\frac{\operatorname{Sinh}\left(\frac{x_{1}}{L_{p}}\right)\left(-f(\lambda)\left(f(\lambda)^{2} L_{p}^{2}-1\right)\left(f(\lambda) D_{p}+S_{p}\right)+\lambda f^{\prime}(\lambda)\left(\left(f(\lambda) D_{p}\right)\left(2+f(\lambda) x_{1}\right)\left(f(\lambda)^{2} L_{p}^{2}-1\right)+S_{p}\left(1-f(\lambda) x_{1}+f(\lambda)^{2}\left(1+f(\lambda) x_{1}\right)\right)\right)\right)}{\left(L_{p}^{2} f(\lambda)^{2}-1\right)^{2}\left(D_{p} \operatorname{Cosh}\left(\frac{x_{1}}{L_{p}}\right)+L_{p} S_{p} \operatorname{Sinh}\left(\frac{x_{1}}{L_{p}}\right)\right)}
\end{array}\right) \\
& \int \frac{L_{n-s u b} f(\lambda)^{2} e^{-f(\lambda) x_{2}}+f(\lambda) e^{-f(\lambda) x_{2}} \operatorname{Coth}\left(\frac{x_{2}-x_{3}}{L_{n-s u b}}\right)-f(\lambda) e^{-f(\lambda) x_{3}} \operatorname{Csch}\left(\frac{x_{2}-x_{3}}{L_{n-s u b}}\right)}{\left(L_{n-s u b}^{2} f(\lambda)^{2}-1\right)} \\
& +\frac{q L_{n-s u b}}{h b}+\frac{L_{n-s u b} \lambda f(\lambda) f^{\prime}(\lambda) e^{-f(\lambda) x_{2}}+\lambda f^{\prime}(\lambda) e^{-f(\lambda) x_{2}} \operatorname{Coth}\left(\frac{x_{2}-x_{3}}{L_{n-s u b}}\right)-\lambda f^{\prime}(\lambda) e^{-f(\lambda) x_{3}} \operatorname{Csch}\left(\frac{x_{2}-x_{3}}{L_{n-s u b}}\right)}{\left(L_{n-s u b}^{2} f(\lambda)^{2}-1\right)} \\
& +\frac{q L_{n-s u b b}}{h c}\left|+\frac{L_{n-s u b} \lambda f(\lambda) f^{\prime}(\lambda) e^{-f(\lambda) x_{2}}-L_{n-s u b} x_{2} \lambda f(\lambda)^{2} f^{\prime}(\lambda) e^{-f(\lambda) x_{2}}-x_{2} \lambda f(\lambda) f^{\prime}(\lambda) \operatorname{Coth}\left(\frac{x_{2}-x_{3}}{L_{n-s u b}}\right)+x_{3} \lambda f(\lambda) f^{\prime}(\lambda) e^{-f(\lambda) x_{3}} \operatorname{Csch}\left(\frac{x_{2}-x_{3}}{L_{n-s u b}}\right)}{\left(L_{n-s u b}^{2} f(\lambda)^{2}-1\right)}\right| \\
& -\frac{2 L_{n-s u b}^{3} \lambda f(\lambda)^{3} f^{\prime}(\lambda) e^{-f(\lambda) x_{2}}+2 \lambda f(\lambda)^{2} f^{\prime}(\lambda) L_{n-s u b}^{2} e^{-f(\lambda) x_{2}} \operatorname{Coth}\left(\frac{x_{2}-x_{3}}{L_{n-s u b}}\right)-2 \lambda f(\lambda)^{2} f^{\prime}(\lambda) L_{n-s u b}^{2} b^{-f(\lambda) x_{3}} \operatorname{Csch}\left(\frac{x_{2}-x_{3}}{L_{n-s u b}}\right)}{\left(L_{n-s u b}^{2} f(\lambda)^{2}-1\right)^{2}} \\
& \left.+\frac{q}{h c}\left(e^{-f(\lambda)\left(x_{1}+x_{2}\right)}\right)\left(e^{f(\lambda) x_{2}}\left(\lambda f^{\prime}(\lambda) x_{1}-1\right)+e^{f(\lambda) x_{1}}\left(\lambda f^{\prime}(\lambda) x_{2}-1\right)\right)\right)
\end{aligned}
$$

(A5)

The calculation result represents the slope of Eq. (A4). When Eq. (A5) equals to 0, the corresponding $\lambda$ is the peak wavelength of the spectral response.

Equation (A5) is a complex non-exact differential equation. Accordingly, some assumptions are employed to simplify the solution for Eq. (A5). The spectral response induced in the 
space-charge region is generally too small to be neglected. Additionally, diffusion lengths of the minority carriers in $\mathrm{n}$ - and $\mathrm{p}$-substrate are as long as several hundred micrometers owing to low-doped concentrations, and thus wavelengths in the visible region are much smaller than the diffusion lengths. Moreover, there exist the following assumptions

$$
\begin{gathered}
L_{p}^{2} f(\lambda)^{2}-1 \cong L_{p}^{2} f(\lambda)^{2}, \\
L_{n-s u b}^{2} f(\lambda)^{2}-1 \cong L_{n-s u b}^{2} f(\lambda)^{2},
\end{gathered}
$$

and

$$
L_{p} \gg x_{1}
$$

Eq. (A5) can be simplified as follows.

$$
\frac{1}{f(\lambda)^{4}}\left(\begin{array}{l}
f(\lambda)^{4}+f(\lambda)^{4} e^{-f(\lambda) x_{1}}+f(\lambda)^{3} e^{-f(\lambda) x_{1}} \frac{S_{p}}{D_{p}}-2 \lambda f(\lambda) f^{\prime}(\lambda) e^{-f(\lambda) x_{1}} \frac{1}{L_{p}^{2}}-\lambda f^{\prime}(\lambda) e^{-f(\lambda) x_{1}} \frac{S_{p}}{L_{p}^{2} D_{p}} \\
-f(\lambda)^{2} e^{-f(\lambda) x_{1}} \lambda f^{\prime}(\lambda) \frac{S_{p}}{D_{p}}+f(\lambda)^{3} \frac{S_{p}}{D_{p}}+2 \lambda f(\lambda)^{3} f^{\prime}(\lambda)+\lambda f(\lambda)^{4} f^{\prime}(\lambda) x_{1}+\lambda f^{\prime}(\lambda) \frac{S_{p}}{L_{p}^{2} D_{p}}- \\
\lambda f(\lambda) f^{\prime}(\lambda) x_{1} \frac{S_{p}}{L_{p}^{2} D_{p}}+\lambda f(\lambda)^{2} f^{\prime}(\lambda) \frac{S_{p}}{L_{p}^{2} D_{p}}+\lambda f(\lambda)^{3} f^{\prime}(\lambda) x_{1} \frac{S_{p}}{L_{p}^{2} D_{p}}+f(\lambda)^{4} e^{-f(\lambda) x_{2}} \\
+f(\lambda)^{4} e^{-f(\lambda) x_{2}} \frac{1}{L_{n-\text { sub }} f(\lambda)} \operatorname{Coth}\left(\frac{x_{2}-x_{3}}{L_{n-\text { sub }}}\right)-f(\lambda)^{3} e^{-f(\lambda) x_{3}} \frac{1}{L_{n-\text { sub }}} \operatorname{Csch}\left(\frac{x_{2}-x_{3}}{L_{n-\text { sub }}}\right)+\lambda f(\lambda)^{3} f^{\prime}(\lambda) e^{-f(\lambda) x_{2}} \\
+\lambda f(\lambda)^{3} f^{\prime}(\lambda) e^{-f(\lambda) x_{2}} \frac{1}{L_{n-\text { sub }}} \operatorname{Coth}\left(\frac{x_{2}-x_{3}}{L_{n-\text { sub }}}\right)-\lambda f(\lambda)^{2} f^{\prime}(\lambda) e^{-f(\lambda) x_{3}} \frac{1}{L_{n-\text { sub }}} \operatorname{Csch}\left(\frac{x_{2}-x_{3}}{L_{n-\text { sub }}}\right) \\
+\lambda f(\lambda)^{4} f^{\prime}(\lambda) e^{-f(\lambda) x_{3}} x_{3} \frac{1}{L_{n-\text { sub }} f(\lambda)} \operatorname{Csch}\left(\frac{x_{2}-x_{3}}{L_{n-\text { sub }}}\right)-2 \lambda f^{4}(\lambda)^{3} f^{\prime}(\lambda) e^{-f(\lambda) x_{2}} \\
-2 \lambda f(\lambda)^{2} f^{\prime}(\lambda) e^{-f(\lambda) x_{2}} \frac{1}{L_{n-\text { sub }}} \operatorname{Coth}\left(\frac{x_{2}-x_{3}}{L_{n-s u b}}\right)+2 \lambda f(\lambda)^{2} f^{\prime}(\lambda) e^{-f(\lambda) x_{3}} \frac{1}{L_{n-\text { sub }}} \operatorname{Csch}\left(\frac{x_{2}-x_{3}}{L_{n-\text { sub }}}\right)=0
\end{array}\right.
$$

\section{Acknowledgement}

This work was partially supported by National Science Council, Taiwan, under the contract number of NSC 97-2221-E-194-060-MY3.

\section{References}

[1] B. E. Bayer, “Color Imaging Array,” U. S. Patent 3971065, July 1976.

[2] W. J. Liu, Oscal T.-C. Chen, L. K. Dai, P. K. Weng, K. H. Huang and Far-Wen Jih, “A CMOS photodiode model," Proc. of IEEE International Workshop on Behavioral Modeling and Simulation, pp. 102-105, 2001.

[3] K. C. Chang, C. Y. Chang, Y. K. Fang and S. C. Jwo, "The amorphous Si/SiC heterojunction color-sensitive phototransistor," IEEE Electron Device Letters, vol. 8, no. 2, pp. 64-65, 1987. 
[4] H. K. Tsai, S. C. Lee and W. L. Lin, "An amorphous SiC/Si two-color detector," IEEE Electron Device Letters, vol. 8, no. 8, pp. 365-367, 1987.

[5] Y. K. Fang, S. B. Hwang, K. H. Chen, C. R. Liu, M. J. Tsai and L. C. Kuo, "An amorphous $\mathrm{SiC} / \mathrm{Si}$ heterojunction $\mathrm{p}-\mathrm{i}-\mathrm{n}$ diode for low-noise and high-sensitivity UV detector," IEEE Trans. on Electron Devices, vol. 39, no. 2, pp. 292-296, 1992.

[6] Y. K. Fang, S. B. Hwang, K. H. Chen, C. R. Liu, M. J. Tsai and L. C. Kuo," A metalamorphous silicon-germanium alloy Schottky barrier for infrared optoelectronic IC on glass substrate application," IEEE Trans. on Electron Devices, vol. 39, no. 6, pp. 1348-1354, 1992.

[7] G. de Cesare, F. Irrera, F. Lemmi and F. Palma, "Tunable photodetectors based on amorphous $\mathrm{Si} / \mathrm{SiC}$ heterostructures," IEEE Trans. on Electron Devices, vol. 42, no. 5, pp. 835-840, 1995.

[8] K. Eberhardt, T. Neidlinger and M. B. Schubert, "Three-color sensor based on amorphous n-i-p-i-n layers sequence," IEEE Trans. on Electron Devices, vol. 42, no. 10, pp. 1763$1768,1995$.

[9] J. Zimmer, D. Knipp, H. Stiebig and H. Wagner, “Amorphous silicon-based unipolar detector for color recognition," IEEE Trans. on Electron Devices, vol. 46, no. 5, pp. 884-891, 1999.

[10] M. Topic, H. Stiebig, D. Knipp and F. Smole, "Optimization of a-Si:H-based threeterminal three-color detectors," IEEE Trans. on Electron Devices, vol. 46, no. 9, pp. 1839-1845, 1999.

[11] T. Su, P. C. Taylor, G. Ganguly and D. E. Carlson, "Direct role of hydrogen in the Staebler-Wronski effect in hydrogenated amorphous silicon," Physical Review Letters, vol. 89, no. 1, pp. 015502-1-015502-4, 2002.

[12] T. Lule, M. Wagner, M. Verhoeven, H. Keller and M. Bohm, “100000-pixel, 120-dB imager in TFA technology," IEEE Journal of Solid-State Circuits, vol. 35, no. 5, pp. 732-739, 2000.

[13] Masahiro Kasano, Yuichi Inaba, Mitsuyoshi Mori, Shigetaka Kasuga, Takahiko Murata and Takumi Yamaguchi, “A 2.0- $\mu \mathrm{m}$ pixel pitch CMOS image sensor with 1.5 transistor/pixel and an amorphous Si color filter," IEEE Trans. on Electron Devices, vol. 53, no. 4, pp. 611-617, 2006.

[14] Foveon Inc, "Color separation in an active pixel cell imaging array using a triple-well structure," U.S. Patent 5965 875, 12 Oct. 1999.

[15] K. M. Findlater, D. Renshaw, E. D. Hurwitz, R. K. Henderson, M. D. Percell, S. G. Smith and T. E. R. Bailey, "A CMOS image sensor with a double-junction active pixel," IEEE Trans. on Electron Devices, vol. 50, no.1, Jan. 2003.

[16] W. J. Liu, O. T.-C. Chen, L. K. Dai, P. K. Weng, K. H. Huang and F. W. Jih, “A color image sensor using adaptive color pixels," Proc. of IEEE Midwest Symposium on Circuits and Systems, vol. 2, pp. 441-444, Aug. 2002.

[17] Giacomo Langfelder, Federico Zaraga and Antonio Longoni, "Tunable spectral responses in a color-sensitive CMOS pixel for imaging applications," IEEE Trans. on Electron Devices, vol. 56, no. 11, pp. 2563-2569, 2009.

[18] Antonio Longoni, Federico Zaraga, Giacomo Langfelder, and Luca Bombelli, "The transverse field detector (TFD): a novel color-sensitive CMOS device," IEEE Trans. on Electron Devices, vol. 29, no. 12, pp. 1306-1308, 2008.

[19] K. De Munck, D. Sabuncuoglu Tezcan, T. Borgers, W. Ruythooren, P. De Moor, S. Sedky, C. Toccafondi, J. Bogaerts and C. Van Hoof, "High performance hybrid and monolithic backside thinned CMOS imagers realized using a new integration process," Proc. of IEEE IEDM, pp. 1-4, 2006. 
[20] M. Bartek, P. T. J. Gennissen, P. Sarro, P. J. French and R. F. Wolffenbuttel, “An integrated silicon color sensor using selective epitaxial growth," Sensors and Actuators A: Physical, vol. 41, no. 1-3, pp. 123-128, 1994.

[21] R. F. Wolffenbuttel, "Color filters integrated with the detector in silicon," IEEE Electron Device Letters, vol. 8, no. 1, pp. 13-15, 1987.

[22] Oscal T.-C. Chen, W. J. Liu, L. K. Dai, P. K. Weng, K. H. Huang and Far-Wen Jih, "Extended one-dimensional analysis to effectively derive quantum efficiency of various CMOS photodiodes," IEEE Trans. on Electron Devices, vol. 54, no. 10, pp. 2659-2668, 2007.

[23] E. R. Fossum, "CMOS image sensor: electronic camera on a chip," Tech. Dig. of IEEE IEDM, pp. 17-25, Dec. 1995.

[24] A. El Gamal and H. Eltoukhy, "CMOS image sensors," IEEE Circuits and Devices Magazine, vol. 21, no. 3, pp. 6-20, May/June 2005.

[25] Isao Takayanagi, Miho Shirakawa, Koji Mitani, Masayuki Sugawara, Steinar Iversen, Jørgen Moholt, Junichi Nakamura and Eric R. Fossum, “A 1.25-inch 60-frames/s 8.3-M-pixel digital-output CMOS image sensor," IEEE Journal of Solid-State Circuits, vol. 40, no. 1, pp. 2305-2314, 2005.

[26] K. Fife, A. El Gamal and H.-S. P. Wong, "A multi-aperture image sensor with 0.7um pixels in 0.11um CMOS technology," IEEE Journal of Solid-State Circuits, vol. 43, no. 12, pp. 2990-3005, 2008.

[27] D. S. Tezcan, S. Eminoglu and T. Akin, "A low-cost uncooled infrared microbolometer detector in standard CMOS technology," IEEE Trans. on Electron Devices, vol. 50, no. 2, pp. 494-502, 2003.

[28] C. C. Liu and C. H. Mastrangelo, "A CMOS uncooled heat-balancing infrared imager," IEEE Trans. on Electron Devices, vol. 35, no. 4, pp. 527-535, 2000.

[29] C. I. Drowley, M.S. Swenson, L. Arbaugh, R. Hollstein, F. Shapiro, and S. Domer, “A 0.6 um CMOS pinned photodiode color imager technology," Tech. Digest of IEEE IEDM, pp. 927-929, 1997.

[30] S. M. Sze, Physics of Semiconductor Devices, New York: John Wiley and Sons, Inc., 1980.

[31] C. Y. Wu and C. F. Chiu, "A new structure of the 2-D silicon retina," IEEE Journal of Solid-State Circuits, vol. 30, no. 8, pp. 890-897, 1995.

[32] Y. Huang and R. I. Hornsey, "Current-mode CMOS image sensor using lateral bipolar phototransistors," IEEE Trans. on Electron Devices, vol. 50, no. 12, pp. 2570-2573, 2003.

[33] Xin Liu, Shuxu Guo, Chen Zou, Guotong Du, Yuqi Wang and Yuchun Chang, "Punchthrough enhanced phototransistor fabricated in standard CMOS process," IEEE Electron Device Letters, vol. 30, no. 3, pp. 272-274, 2009.

[34] C. Y. Wu, H. D. Sheng and Y. T. Tsai, "The lambda bipolar phototransistor-analysis and applications," IEEE Journal of Solid-State Circuits, vol. 20, no. 6, pp. 1227-1234, 1985.

[35] R. R. King, R. A. Sinton and R. M. Swanson, "Studies of diffused phosphorus emitters: saturation current, surface recombination velocity, and quantum efficiency," IEEE Trans. on Electron Devices, vol. 37, no. 2, pp. 365-371, 1990.

[36] R. R. King and R. M. Swanson, "Studies of diffused boron emitters: saturation current, bandgap narrowing, and surface recombination velocity," IEEE Trans. on Electron Devices, vol. 38, no. 6, pp. 1399-1409, 1991.

[37] D. K. Schroder, Semiconductor Material and Device Characterization, New York: John Wiely \& Sons, pp. 420-508, 1998. 


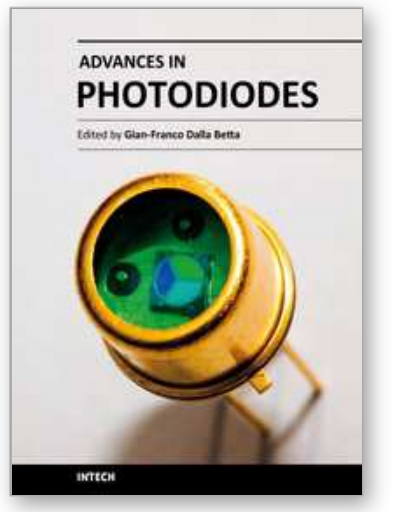

\author{
Advances in Photodiodes \\ Edited by Prof. Gian Franco Dalla Betta
}

ISBN 978-953-307-163-3

Hard cover, 466 pages

Publisher InTech

Published online 22, March, 2011

Published in print edition March, 2011

Photodiodes, the simplest but most versatile optoelectronic devices, are currently used in a variety of applications, including vision systems, optical interconnects, optical storage systems, photometry, particle physics, medical imaging, etc. Advances in Photodiodes addresses the state-of-the-art, latest developments and new trends in the field, covering theoretical aspects, design and simulation issues, processing techniques, experimental results, and applications. Written by internationally renowned experts, with contributions from universities, research institutes and industries, the book is a valuable reference tool for students, scientists, engineers, and researchers.

\title{
How to reference
}

In order to correctly reference this scholarly work, feel free to copy and paste the following:

Oscal T.-C. Chen and Wei-Jean Liu (2011). Color-Selective CMOS Photodiodes Based on Junction Structures and Process Recipes, Advances in Photodiodes, Prof. Gian Franco Dalla Betta (Ed.), ISBN: 978-953-307-1633, InTech, Available from: http://www.intechopen.com/books/advances-in-photodiodes/color-selective-cmosphotodiodes-based-on-junction-structures-and-process-recipes

\section{INTECH}

open science | open minds

\section{InTech Europe}

University Campus STeP Ri Slavka Krautzeka 83/A 51000 Rijeka, Croatia Phone: +385 (51) 770447 Fax: +385 (51) 686166 www.intechopen.com

\section{InTech China}

Unit 405, Office Block, Hotel Equatorial Shanghai No.65, Yan An Road (West), Shanghai, 200040, China 中国上海市延安西路65号上海国际贵都大饭店办公楼 405 单元 Phone: +86-21-62489820

Fax: $+86-21-62489821$ 
(C) 2011 The Author(s). Licensee IntechOpen. This chapter is distributed under the terms of the Creative Commons Attribution-NonCommercialShareAlike-3.0 License, which permits use, distribution and reproduction for non-commercial purposes, provided the original is properly cited and derivative works building on this content are distributed under the same license. 